\title{
Transient thermocapillary flow in rectangular tanks with phase change
}

\author{
C. Y. SHIEH and WEN-JEI YANG \\ Mechanical Engineering and Applied Mechanics, University of Michigan, Ann Arbor, MI 48109, U.S.A.
}

(Received 14 January 1986 and in final form 25 August 1986)

\begin{abstract}
A numerical and experimental study is performed on transient natural convection in an insulated rectangular tank. The liquid is suddenly heated by a line source or cooled by a line sink being placed at the center of the free surface to initiate a thermocapillary force. Evaporation or condensation takes place on the free surface. A finite-difference technique is employed to numerically integrate the unsteady vorticity and heat transport equations. Numerical results are obtained to determine the effects of dimensionless governing parameters on the transfer phenomena. In an evaporative system with low Marangoni number $(M a)$, three distinct convective mechanisms are identified: surface tension-driven, buoyancy-driven and mixed types. The differences in the flow behavior are disclosed between condensation, evaporation and no phase change. Theory is in qualitative agreement with evaporation experiments in
\end{abstract} high $M a$ systems.

\section{INTRODUCTION}

THE ADVENT of material processing in a reducedgravitational environment has motivated a substantial interest in thermocapillary flow phenomena. Natural convection in open containers may be desirable in processes occurring in space, e.g. to mingle the fluid phase for mixing or cooling purposes or to help maintain concentration gradients. Spacelab 1 experiment IES 328 was devised to examine natural convection under low gravity conditions for configuration modelling the floating-zone method used in the growth of superpure single crystal [1]. A melting zone (i.e. liquid bridge) is suspended between the top rod (a polycrystalline feed material) and the bottom rod (a pure, single crystal) by surface tension. The size and property of the crystal grown by this method are affected by the flow phenomena in the melting zone.

Under normal gravity, Burgoyne et al. [2] studied the natural convection pattern and buoyancy layer within the liquid layer ahead of the propagating flame front as the flame spread across the free surface of a flammable liquid. The phenomenon was the Rayleigh and Marangoni convection resulting from surface tension gradients at the free surface caused by heat transfer from the flame front. In welding, the flow in the molten pool is of interest, because it affects the temperature distribution in and around the molten zone which can alter the weld shape, and because it controls the transport of surface contaminants into the substrates [3,4]. This is also truc in the case of surface processing where the flow in the molten pool controls the transport of alloying or doping materials into the substrate. It is known that interfacial convection induced by surface tension gradients causes a significant boost in both heat and mass transfer [5]. Zhang and Yang [6] determined flow structures induced by the interaction of buoyancy and surface tension mechanisms in minute drops evaporating on plates.

There is no theoretical or experimental study on the buoyancy-Marangoni convection in a liquid undergoing phase change. The purpose of the present study is to understand the complex mechanisms associated with heat transport in an insulated rectangular tank with a liquid undergoing phase change, with the combination of surface tension and normal, reduced and micro-gravity environments. Ethyl alcohol is heated by a wire placed at the center of the free surface to initiate a thermocapillary force. Phase change takes place on the free surface. A finitedifference technique is employed to numerically integrate the unsteady two-dimensional vorticity and heat transport equations. The effects of the dimensionless physical and geometrical parameters on the transport phenomena are determined. The analytical results are compared with those obtained experimentally. The flow bahaviors under condensation and no phase change are also theoretically determined for comparison with the evaporation case.

\section{THEORY}

Consider a rectangular tank filled with a liquid undergoing phase change. Cartesian coordinates $(x, y, z)$ are employed with the origin fixed at a midplane along the bottom, as shown in Fig. 1. The tank is two-dimensional in the $y$-and $z$-directions. A heating wire, considered a line heat source, is placed at the free surface parallel to the $x$-axis. To enhance the interfacial transport phenomena, the lateral and lower boundaries of the tank of depth $H$ and width $2 L$ are insulated. The ambient temperature is $T_{\infty}$. Initially, the wire and liquid are at a uniform tempera- 


\section{NOMENCLATURE}

$A$ free surface area $\left[\mathrm{m}^{2}\right]$

Ev evaporation number, $m H h_{\mathrm{fg}} / k A \Delta t$; negative for evaporation and positive for condensation

$g$ gravitational acceleration $\left[\mathrm{m} \mathrm{s}^{-2}\right]$

$H$ depth of liquid layer [m]

$h_{\mathrm{fg}} \quad$ latent heat of evaporation [ $\left.\mathrm{kJ} \mathrm{kg}{ }^{1}\right]$

$k$ thermal conductivity $\left[\mathrm{W} \mathrm{m}^{-1} \mathrm{~K}^{-1}\right]$

$L$ one-half width of liquid layer [m]

Ma Marangoni number, $(L \Delta T / \mu \alpha)(\partial S / \partial T)_{T_{\infty}}$ $m$ rate of phase change $\left[\mathrm{kg} \mathrm{s}^{-1}\right]$

$P e \quad$ Peclet number, $|V| \Delta / \alpha$

$p \quad$ liquid pressure $\left[\mathrm{N} \mathrm{m}^{-2}\right]$

$R a$ Rayleigh number, $g \beta H^{3} \Delta T / v \alpha ; R a_{c}$, transition from the $M a$-driven convection to the mixed convection; $R a_{t}$, transition from the mixed convection to the $R a$-driven convection

$S \quad$ surface tension $\left[\mathrm{N} \mathrm{m}^{-1}\right]$

$T$ liquid temperature [ $\left.{ }^{\circ} \mathrm{C}\right]$

$T_{0} \quad$ line source or sink temperature $\left[{ }^{\circ} \mathrm{C}\right]$

$T_{\infty} \quad$ initial liquid temperature (also ambient temperature) $\left[{ }^{\circ} \mathrm{C}\right]$

$\Delta T \quad\left|T_{\infty}-T_{0}\right|\left[{ }^{\circ} \mathrm{C}\right]$

$t \quad$ time [s]

$V \quad$ relevant fluid velocity $\left[\mathrm{m} \mathrm{s}^{-1}\right]$ $v$ velocity component in $y$-direction $\left[\mathrm{m} \mathrm{s}^{-1}\right]$

$w$ velocity component in $z$-direction $\left[\mathrm{m} \mathrm{s}^{-1}\right]$

$y$ distance measured from centerline of tank $[\mathrm{m}]$

$z$ distance measured from bottom of tank [m].

Greek symbols

$\alpha$ thermal diffusivity $\left[\mathrm{m}^{2} \mathrm{~s}^{-1}\right]$

$\beta$ coefficient of thermal expansion $\left[\mathrm{K}^{-1}\right]$

$\Delta$ mesh width [m]

$\mu$ dynamic viscosity $\left[\mathrm{kg} \mathrm{m}^{-1} \mathrm{~s}^{-1}\right]$

$v \quad$ kinematic viscosity $\left[\mathrm{m}^{2} \mathrm{~s}^{-1}\right]$

$\rho \quad$ liquid density $\left[\mathrm{kgm}^{-3}\right], \rho_{\infty}$, at $T_{\infty}$

$\psi$ stream function $\left[\mathrm{s}^{-1}\right],\left|\psi_{\max }\right|$, maximum value.

\section{Subscripts}

0 line source

$\infty$ initial state, also ambient

c transition from the $\mathrm{Ma}$-driven flow to the mixed flow

t transition from the mixed flow to the $R a$ driven flow.

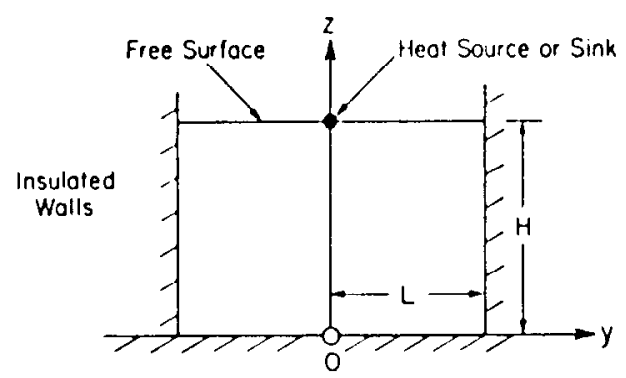

FIG. 1. A schematic of the physical system.

ture of $T_{\infty}$. The wire is then suddenly raised to $T_{0}$ by passing an electric current through the wire. Heat is then transferred from the wire to the liquid at temperatuare $T(y, z, t)$. The task is to determine the changes in temperature and stream function as functions of time and location. The Peclet number will be employed to express the domain of influence exerted by buoyancy-thermocapillary forces.

The following assumptions are imposed in simplifying the problem: an incompressible fluid; negligible heating effects by pressure and viscosity; and constant physical properties except fluid density which changes linearly with temperature as

$$
\rho=\rho_{\infty}\left[1+\beta\left(T-T_{\infty}\right)\right] .
$$

The governing equations read

$$
\begin{gathered}
\text { energy } \frac{\partial T}{\partial t}+v \frac{\partial T}{\partial y}+w \frac{\partial T}{\partial z}=\alpha\left(\frac{\partial^{2} T}{\partial y^{2}}+\frac{\partial^{2} T}{\partial z^{2}}\right) \\
\text { continuity } \frac{\partial v}{\partial y}+\frac{\partial w}{\partial z}=0
\end{gathered}
$$

momentum

$$
\rho \frac{\partial v}{\partial t}+v \frac{\partial v}{\partial y}+w \frac{\partial v}{\partial z}=-\frac{\partial P}{\partial y}+\mu\left(\frac{\partial^{2} v}{\partial y^{2}}+\frac{\partial^{2} v}{\partial z^{2}}\right)
$$

$$
\rho \frac{\partial w}{\partial t}+v \frac{\partial w}{\partial y}+w \frac{\partial w}{\partial z}=-\frac{\partial P}{\partial z}+\mu\left(\frac{\partial^{2} w}{\partial y^{2}}+\frac{\partial^{2} w}{\partial z^{2}}\right)-\rho g
$$

The appropriate initial and boundary conditions are

$$
\begin{aligned}
v(y, z, 0) & =w(y, z, 0)=0, T(y, z, 0) \\
& =T_{\infty}, T(0, H, 0)=T_{0} \\
v(y, 0, t) & =w(y, 0, t)=v(L, z, t) \\
& =w(L, z, t)=v(0, z, t)=0
\end{aligned}
$$

$\mu \frac{\partial v(y, H, t)}{\partial z}=$

$$
-\left(\frac{\partial s}{\partial T}\right)_{T_{x}} \frac{\partial T(y, H, t)}{y \partial z} ; w(y, H, t)=0
$$




$$
\begin{array}{r}
\frac{\partial T(L, z, t)}{\partial y}=\frac{\partial T(y, 0, t)}{\partial z}=\frac{\partial T(0, z, t)}{\partial y}=0 \\
-k \frac{\partial T(y, H, t)}{\partial z}=\frac{h_{\mathrm{fz}} m}{A} .
\end{array}
$$

The assumption of uniform evaporation is justisfied, since the interfacial temperature difference is less than $\Delta T=0.14^{\circ} \mathrm{C}$ determined experimentally (Fig. 5(a) also reveals a near uniformity in the evaporation rate). The equations of motion are cast into a stream function-vorticity form. The finite-difference expressions are derived for the energy and vorticity transport equations as well as the stream function-vorticity equation. Details of the procedure are available in ref. [7].

A finite-difference technique is employed to numerically integrate the unsteady vorticity and heat transport equations. The flow domain of interest is divided into a network of equally-spaced subgrids along the $y$ - and $z$-axes. In order to achieve computer-time savings, the alternative direction implicit (ADI) method is selected which employs the fractional time step concept to generate tridiagonal matrices $[8,9]$. For example, in a two-dimensional problem as in the present case, all derivatives in the $y$-direction are treated implicitly, while the counterparts in the $z$ direction are represented explicitly over the first halftime step. Over the second half-time step, however, the $y$-and $z$-derivatives are then given explicit and implicit approximations, respectively. In the present work, the central-difference scheme is used to approximate the convection terms. It is known to offer satisfactory results provided that convection does not dominate diffusion. However, when the convection effect becomes dominant, the central-difference approximation for convection is known to result in instability or non-physical oscillatory performance in most circumstances [10]. In order to avoid convective instability, the grid or cell Peclet number must not exceed 2 for the entire calculation $[7,11]$. The Peclet number is defined as $|V| \Delta / \alpha$ where $V$ is the relevant fluid velocity, $\Delta$ is the mesh width and $\alpha$ denotes the thermal diffusivity. The convergence criterion is set at $1 \%$ of the difference between two consecutive time instants for vortices and velocities.

The computation procedure consists of the following sequence: (1) new temperatures, (2) new interior vortices, (3) new stream functions corresponding to the new interior vortices and the boundary vortices of the previous time instant, (4) new velocity components, (5) new boundary vortices until the convergence criterion is satisfied, (6) check the convergence criterion for the new velocities, update the velocities by replacing them by the arithmetical averages of the new and previous values, and return to the first step for reiteration, (7) check the convergence criterion for the boundary vortices, update the vortices with the

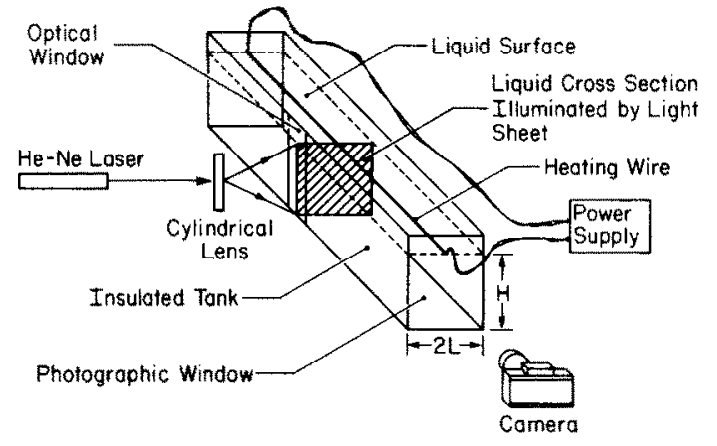

FiG. 2. A schematic of the experimental setup.

current values, and return to the first step for reiteration, and (8) increase the time increment and return to the first step.

\section{EXPERIMENTS}

Experiments were conducted to visualize the flow pattern and isotherms. The apparatus consisted of three parts: an optical device, a test container, and a heating equipment. The test container was $5 \mathrm{~cm}$ wide $(2 L), 8.6 \mathrm{~cm}$ high $(H)$, and $19 \mathrm{~cm}$ long and was made of $2.54 \mathrm{~cm}$ styrofoam, as shown in Fig. 2. It had one end window and one side window, which were made of acrylic, to allow light to pass through. The heating equipment included a variable voltage power supply $(0-11 \mathrm{~V}$ at a current greater than $1 \mathrm{~A})$ and a heating source made of Nichrome wire $0.064 \mathrm{~mm}$ in diameter.

\subsection{Streamlines}

A beam from a laser was expanded by a cylindrical lens to form a light sheet. Aluminum powders (about $0.05 \mathrm{~mm}$ ) were used as a tracer in flow visualization. The heating wire was suspended on the center of the free surface and could be adjusted by screws. A copper-constantan thermocouple measured the temperature around the line source. The wire temperature was detemined by extrapolating the measured interfacial temperature surrounding the wire. The liquid level dropped by $0.002 \mathrm{~cm}$ (calculated) during $10 \mathrm{~min}$ of temperature-measurement time, which is small compared with the wire diameter, $0.0064 \mathrm{~cm}$. The wire temperature thus obtained was different from the theoretical prediction by less than $20 \%$ as shown in Figs. 7-12 of ref. [7].

The container was filled to the desired level with ethyl alcohol. The liquid was covered by a plastic film to prevent evaporation before the experiment, eliminating the occurrence of initial natural convection within the liquid. To begin the experiment, the plastic film was removed, the laser was turned on, and about $1 \mathrm{ml}$ of the alcohol solution containing aluminum powders was poured into the liquid. After the power supply (present at $6 \mathrm{~V}$ ) was turned on, photographs were taken at different time intervals 
using Polaroid films. The temperature of the liquid surface around the wire was measured. The evaporation rate was determined by measuring the loss of the alcohol over a period of $3 \mathrm{~h}$.

\subsection{Isotherms}

The same experiments were repeated without a tracer. The method of interference holography was employed to produce interference fringes which represented isotherms in the liquid.

\section{RESULTS AND DISCUSSION}

In the process of nondimensionalizing the heat and vorticity transport equations, the following dimensionless parameters are derived

$$
\begin{gathered}
\text { aspect ratio }(R H L)=\frac{H}{L} \\
\text { Prandtl number }(P r)=\frac{v}{\alpha} \\
\text { Rayleigh number }(R a)=\frac{g \beta H^{3} \Delta T}{v \alpha} \\
\text { Marangoni number }(M a)=\frac{L \Delta T}{\mu \alpha}\left(\frac{\partial S}{\partial T}\right)_{T_{\infty}} \\
\text { evaporation number }(E v)=\frac{m H h_{\mathrm{f} g}}{k A \Delta T} .
\end{gathered}
$$

Here $\Delta T$ denotes $\left|T_{m}-T_{0}\right|$, while $m$ is the rate of phase change. The evaporation number $(E v)$ takes a negative value for evaporation, a positive value for condensation and is zero in the absence of phase change. The flow and thermal behavior in the liquid are governed by the above five independent parameters. In the theoretical study, the parameters were varied to determine their effects on natural convection: $R a=1-10^{6}, M a=0-3000, E v=1$ to $-1, \operatorname{Pr}=0.5-$ 30 , and $R H L=1 / 3-3$. In space flights, where steady accelerations may range from about $10^{-4} \mathrm{~g}$ to about $10^{-9} \mathrm{~g}$ in the earth's orbit, the corresponding $R a$ would be reduced by the same order of magnitude from that which occurs under normal gravity condition.

The flow system was divided into a network of $22 \times 22$ grids, which was selected after a numericalconversion experiment. The corresponding cell Peclet number takes a value of less than 2 throughout the entire flow field over most of the numerical computations. The ratio of the time increment $\Delta t$ to the grid area $\Delta y \Delta z$ in dimensionless form, i.e. $\alpha \Delta t /(\Delta y \Delta z)$, is 25 . An Amdahl 5860 digital computer was used in numerical computations. Up to 300 time steps were needed in each run which consumed about 5 min of machine time. Numerical results indicate the existence of two distinct transfer performances depending upon the magnitude of $M a$ : high and low $M a$ ranges. The critical value, $M a_{\mathrm{s}}$, which divides the two ranges is 1000 for $E v=-1$.

\subsection{High Ma range}

When $M a$ exceeds $M a_{c}$, natural convection is surface-tension controlled in the final stage, irrespective of the magnitude of $R a$. There is a distinct thermal stratification pattern in the surface layer between the surface-tension driven convection and the buoyancydriven mechanism: The former has a positive temperature gradient (temperature increasing from the interface toward the bottom), while the latter is characterized by the opposite thermal stratification, as will be discussed later in Section 4.2.3. The upper left cluster in the isotherms of Fig. 3(a) is induced by the heating process (hence, it is higher than the ambient temperature), while thermal stratification at the upper right side results from the evaporation process. It is evident that if the heat supplied by the line source has not reached the entire surface area of a volatile liquid, the latent heat of evaporation must come from the liquid layer beneath the interface. Therefore the stratification temperature is lower than the ambient temperature. The difference between the two temperature zones enhances the convection as shown in the streamlines. The convection initially results from the surface-tension driving force but is subsequently enhanced by buoyancy force as shown in the sequential demonstrations from (a) to (c) in Fig. 3. The accumulation of the colder thermal stratification in the upper right corner finally creates a cold plume due to the buoyancy effect and forces the eddy toward the heating line as shown in Fig. 3(b). Eventually, the heat source controls the thermal behavior of the whole surface, destroys the cold stratification and plume as shown in Fig. 3(c), and stabilizes the system. Two distinct thermal stratifications prevail in the upper and lower regions of the container. In the lower region, the cold temperature pushes the main eddy back toward the free surface and induces the secondary flow. The speed of the induced convection near the line heat source, shown by constant streamlines, reaches $1 \mathrm{~mm} \mathrm{~s}^{-1}$.

In order to confirm the validity of the theoretical model and its numerical scheme, numerical results are compared with experiments which were conducted on ethyl alcohol under thermal conditions of $T_{\infty}=20^{\circ} \mathrm{C}$ and $\Delta T=0.14^{\circ} \mathrm{C}$. The situation corresponds to $M a=2500$ and $R a=3 \times 10^{5}$. The evaporation rate from the free surface was measured to be $0.02 \mathrm{~g} \mathrm{~h}^{-1}$ after a 3 -h test, or equivalently $E v=-0.8$. Experimental results are depicted in Figs. 4 and 5 . Only the right half of the photographs are considered in the following discussion. Figure 4 demonstrates the streamlines observed in the experiments. There is a similarity in the flow patterns between theoretical and experimental results. At quasi-steady state, a pair of vortices, one on top of another, are faintly visiblc. The secondary eddy, theoretically predicted in Fig. 3 (c) cannot be seen because its strength is one-tenth of that of the main eddy. The isotherms of the same system obtained by interference holography are 

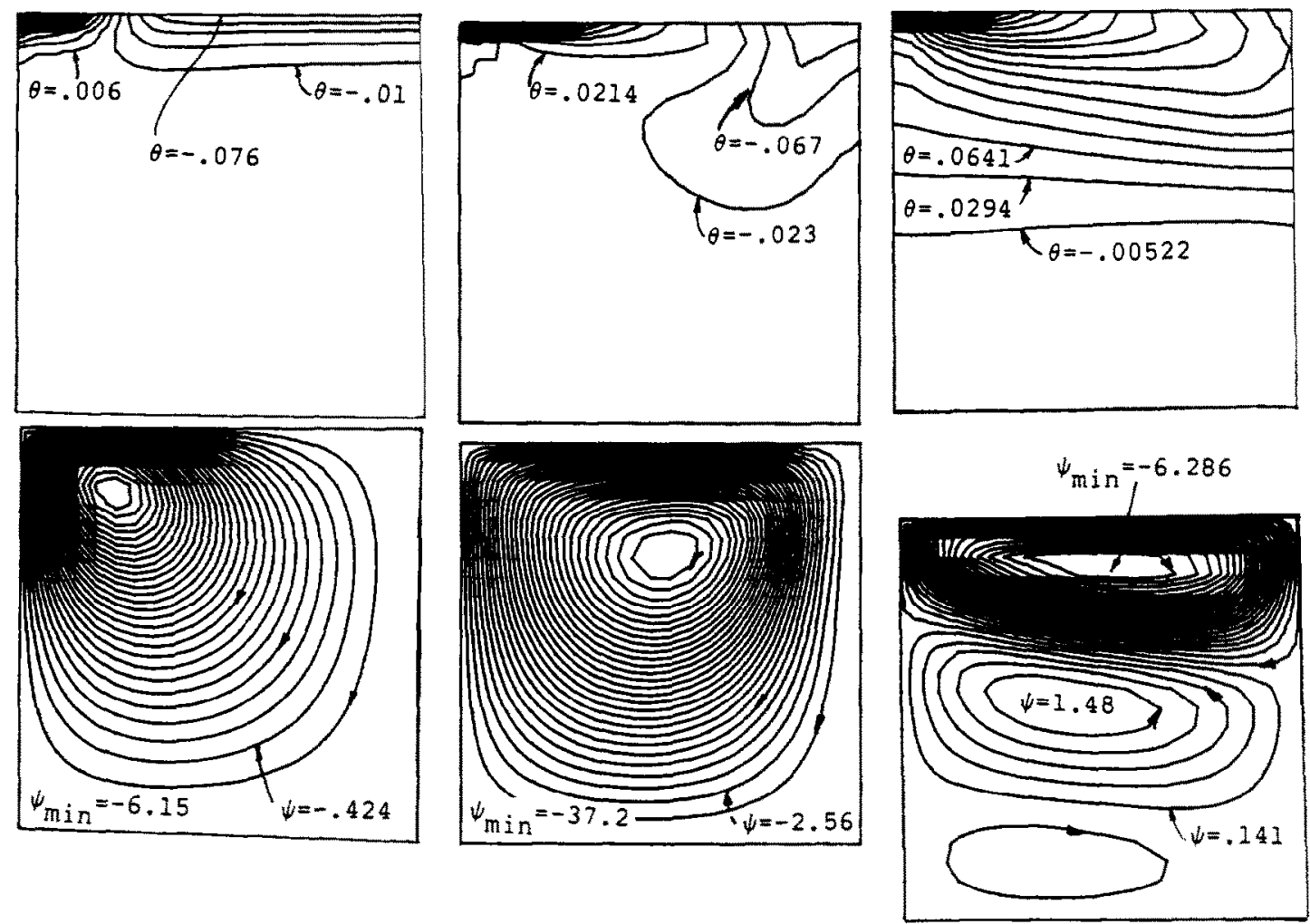

Fig. 3. Timewise variations of isotherms and streamlines in a high $M a$ system with $E v=-1, M a=2500$, $R a=3 \times 10^{5}, \operatorname{Pr}=17.6$ and $R H L=1$.

presented in Fig. 5. The two temperature clusters predicted by the numerical results in Fig. 3(a) are clearly observed in Fig. 5(a). The left cluster results from a mixed action of conduction and convection at the initial state of the heating process, with the lower circulating flow induced by conduction and the oval isotherms extending to the right due to convection. As time elapses, the conduction effect is weakened and the process becomes convection controlled. Therefore, only oval isotherms remain in the upper left, as seen in Fig. 5(b). These isotherms continue to extend toward the walls pushing the right temperature cluster into a thermal plume as predicted by thcory. Both the cold stratification and the plume disappear and the system becomes stabilized when the heat eventually spreads over the entire surface, as depicted in Fig. $5(c)$. The downward stratification along the vertical wall is caused by imperfect insulation of the wall. The validity of the theoretical model and its numerical computation scheme is borne out by the qualitative agreement between the theoretical and numerical results.

\subsection{Low Ma range}

At low Marangoni number, $M a<M a_{\mathrm{c}}$, the numerical study discloses the existence of three types of convection depending on the range of $R a$ : thermocapillary-driven convection, mixed convection and buoyancy-driven convection.
4.2.1. Thermocapillary-driven convection. The buoyancy effect is negligible at low values of $R a$, i.e. $R a<R a_{\mathrm{c}}$. The value of $R a_{\mathrm{c}}$ is about 1000 for $E v=-1$. Surface tension is the only driving force. The upper left cluster represents the warmer fluid migrating to the right, while the upper right cluster at subambient temperature remains stratified, as shown in Fig. 6(a). The absence of a buoyancy effect prevents the formation of a cold plume and the $M a$-driven eddy cannot be developed away from the line source (see Fig. 6(a)) as compared to Fig. 3(b), in which the eddy migrates to the right by the buoyancy effect as time progresses. A steeper surface temperature distribution results in a stronger convection. Numerical results indicate that the steepest temperature slope is located within one-quarter of the width from the line source and that the vortex center is located about one-third of the width from the line source. The absence of a buoyancy effect makes it possible for the warm fluid to migrate downward, Fig. 6(b). As $M a$ decreases, the hot cluster reduces its size and is confined to the space surrounding the line source, while the eddy shape remains the same as that in Fig. 6. However, $\left|\psi_{\max }\right|$ (at steady state for these two cases), decreases sharply from 13 to 1.7. The $M a$-driven flow is unicellular with the vortex center practically fixed at the same site. Its boundary layer is about one-quarter of the depth.

4.2.2. Mixed convection. In the range of $R a_{c}<R a$ 

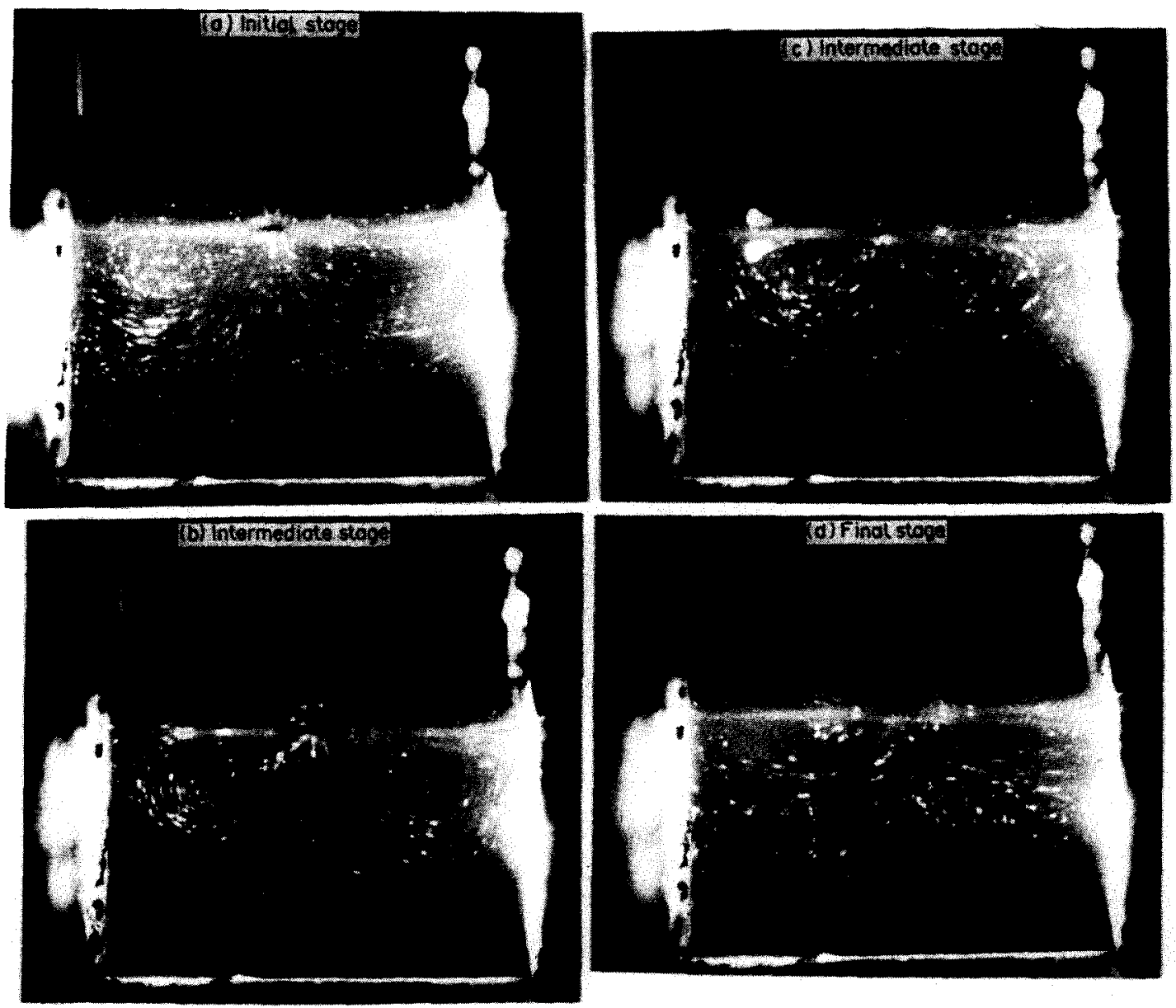

FIG. 4. Timewise variations of streamlines obtained by particle-suspension method in ethyl alcohol with $E v=-0.8, M a=2500, R a=3 \times 10^{5}, \operatorname{Pr}=17.6$ and $R H L=1.1$.

$<R a_{t}$, both surface tension and buoyancy play important roles in flow. The magnitude of $R a_{1}$ is about $10^{5}$ for $E v=-1$. During small times, the warm liquid region is formed around the line source while the hot liquid region appears at the upper right corner of the flow field. They grow toward each other in the layer below the free surface, Fig. 7(a). $\left|\psi_{\max }\right|$ decreases with time, Fig. 8 (points $1-3$ ). In the intermediate stage, the warm stratification region continues to expand toward the wall, while the buoyancy force pulls the cold liquid downward forming a cold plume, Fig. 7 (b). The magnitude of $\left|\psi_{\max }\right|$ bounces back as shown by points $3-6$ in Fig. 8 . In the final stage, the warm cluster prevails over a large portion of the free surface layer, while the cold liquid retreats to the upper right corner (see Fig. 7(c)). At point 6 in Fig. 8 $\left|\psi_{\max }\right|$ takes an asymptotic value. Only a single vortex is observed in the mixed convection. The maximum velocity in the flow field over the entire transient period is about $0.3 \mathrm{~mm} \mathrm{~s}^{-1}$.

4.2.3. Buoyancy-driven convection. Under normal gravity, natural convection in the flow field is most commonly buoyancy-controlled since $R a$ can easily reach or exceed $R a_{\mathrm{t}}$. In the initial stage, a warm cluster is formed around the line source and a cold stratification covers the remaining free surface, triggering the generation of an eddy (Fig. 9(a)). In the intermediate stage, the cold stratification begins to extend downward under the pressure from the oncoming warm cluster. It results in the formation of a cold plume due to a strong buoyancy effect and the generation of a counter eddy in the presence of the opposite temperature field. When the final stage is achieved, the cold cluster adheres to the wall while the counter eddy disappears with the main eddy spreading over the entire flow field, Fig. 9(c). A comparison in the stream function distributions is made between a high $M a$ system in Fig. 3(c) and a low Ma system in Fig. 9(c). It is revealed that a system is stabilized with the appearance of two steady eddies. This interpretation is supported by the fact that when the entire upper domain is covered by the warm liquid as in Fig. 3(c), the cold liquid underneath prevents the upper eddy from moving down and induces the secondary eddy itself. In the lower Ma case, Fig. 9(c), the cold liquid remains at the upper right corner and aids in driving the eddy downward, resulting in a unicellular flow system. 

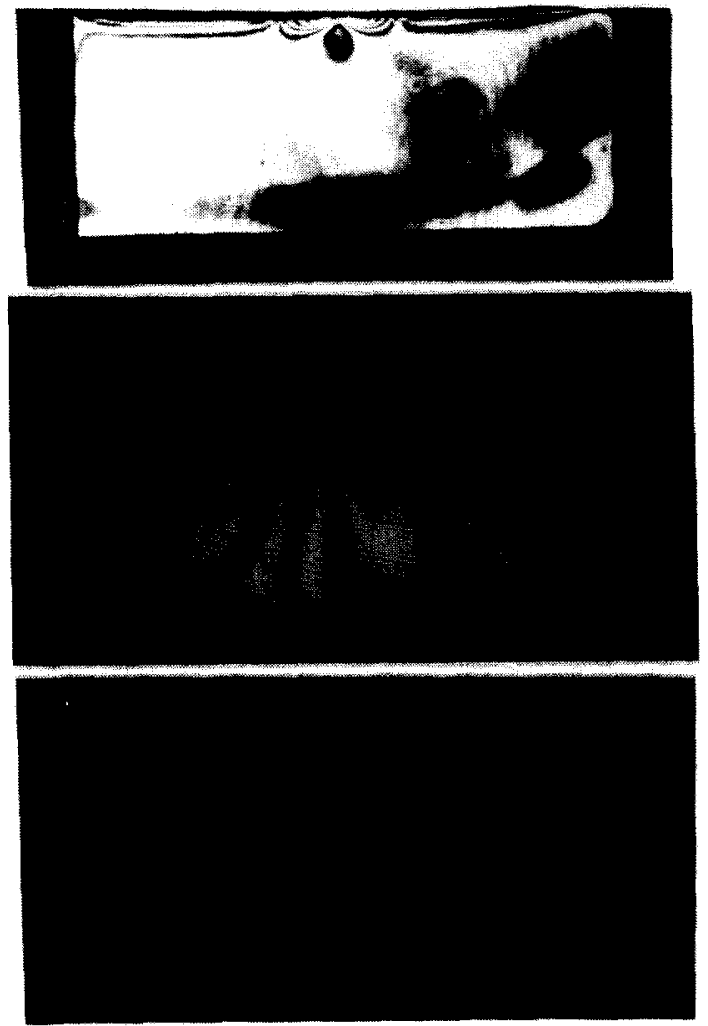

FIG. 5. Timewise variations of isotherms obtained by holographic interferometry in ethyl alcohol with $E v=-0.8$, $M a=2500, R a=3 \times 10^{5}, \operatorname{Pr}=17.6$ and $R H L=0.9$.

\subsection{Parametric study}

The effects of various parameters on flow instability and heat transfer are investigated in the following sections.

4.3.1. Effects of aspect ratio. Under an identical physical situation, a change in the aspect ratio, $R H L=H / L$, varies the magnitude of all governing dimensionless parameters except $P r$. Numerical results for $R H L=0.5$ are presented in Fig. 10 for comparison with Fig. 7 to determine the effects of $R H L$ on the thermocapillary transport in the mixed convection. The shallower depth restricts the expansion of the main body in Fig. 10(a), while a freer growth of the eddy in Fig. 7(a) drives the warm liquid much faster toward the wall. The former case results in a slower convection of the warm liquid and consequently the development of a cold plume covering almost the entire field in the intermediate stage. A large counter eddy is formed in the entire region with opposite temperature gradients, Fig. 10(b). In the final stage, the counter eddy disappears with the plume covering the wall (Fig. 10(c)). In the early stage, the tank bottom in the shallower tank retards the convection, while a free expansion of the eddy in the deeper tank promotes the flow. However, the effect of the tank bottom becomes unimportant in the final stage, since significant temperature gradients exist only in the fluid layer beneath the free surface in both tanks (Figs. 7(c) and 10(c)).

4.3.2. Effects of evaporation number. In the absence of phase change at the free surface, i.e. $E v=0$, no
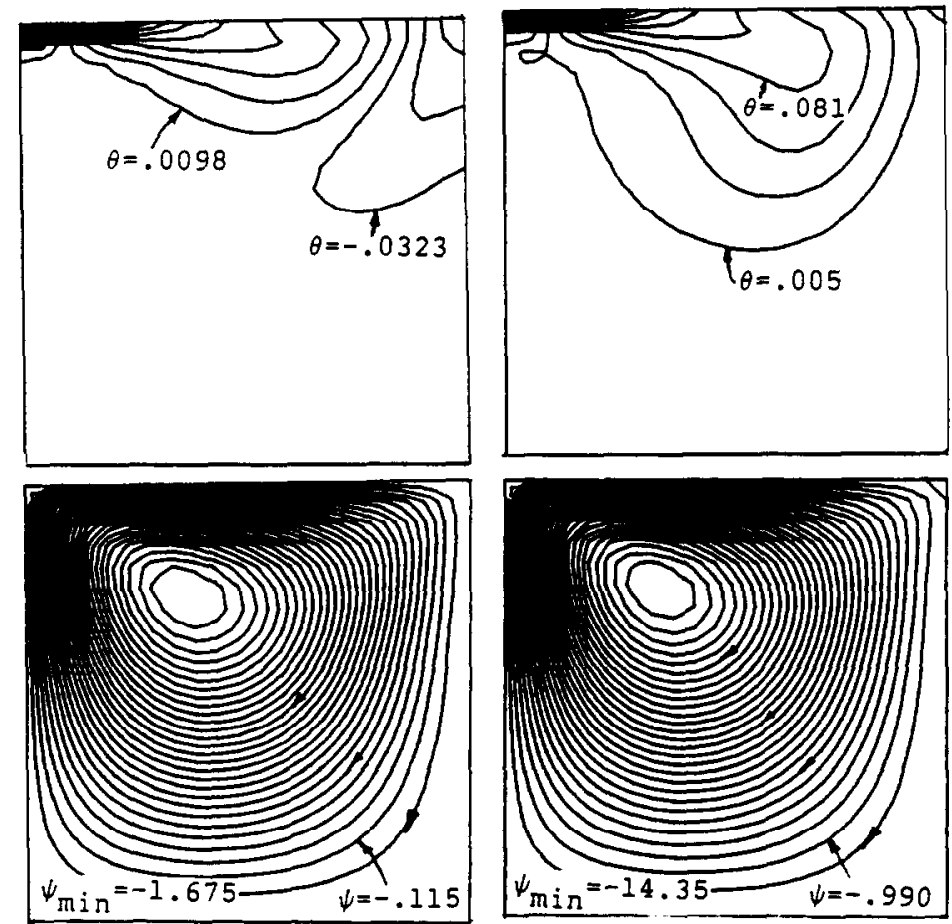

FIG. 6. Timewise variations of isotherms and streamlines in the surface tension-driven convection in a low $M a$ system with $E v=-1, M a=1000, R a=30, \operatorname{Pr}=17.6$ and $R H L=1$. 

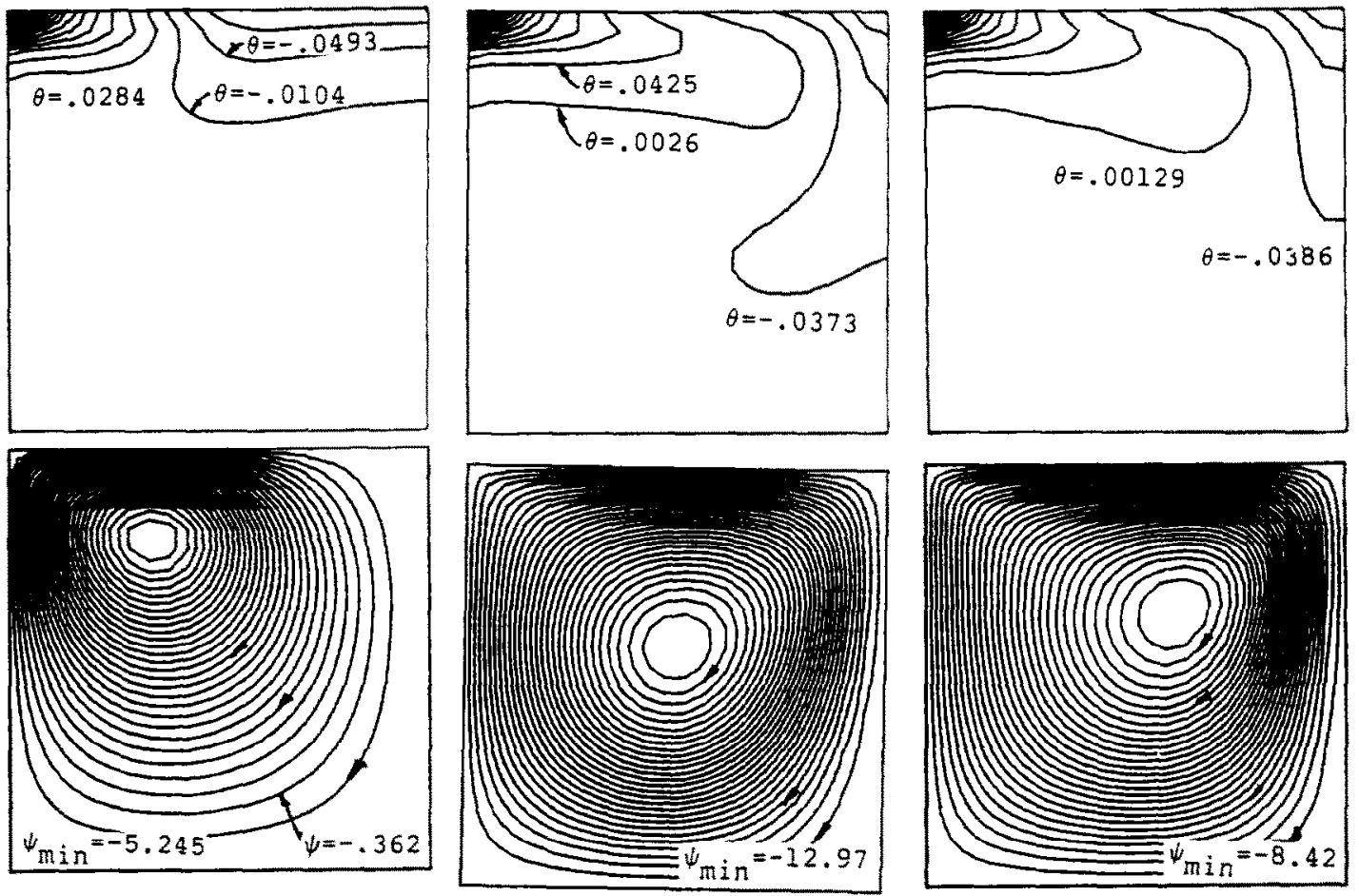

FIG. 7. Timewise variations of isotherms and streamlines in the mixed convection in a low Ma system with $E v=-1, M a=100, R a=10^{5}, \operatorname{Pr}=5$ and $R H L=1$.

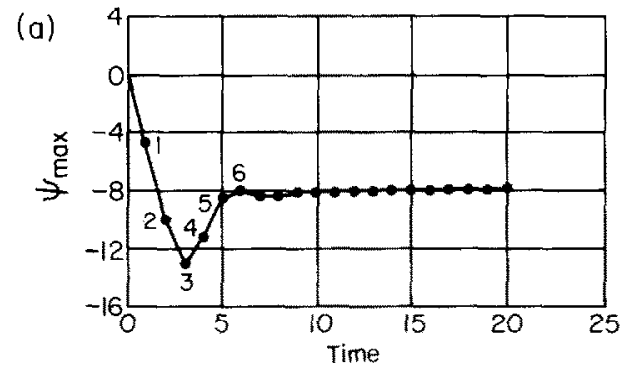

Fig. 8. Time history of the maximum stream function $\psi_{\max }$ in the mixed convection in a $M a$ system with $E v=-1$, $M a=100, R a=10^{5}, \operatorname{Pr}=5$ and $R H L=1$.

cold liquid stratification appears. During the early stage, the convection is driven mainly by the surface tension gradient and the vortex is located near the line source (Fig. 11(a)). As time elapses, the warm liquid cluster expands toward the wall and the vortex center moves toward the wall due to buoyancy (Fig. 11(b)). However, the vortex center does not move downward, due to a lack of the pulling force induced by cold plumes. In the final stage when the development of the eddy is hindered by the wall, the vortex is held back and begins to shrink toward the free surface. A counter eddy is formed in the cold liquid domain beneath the warm cluster to retard the downward motion of the warm liquid (Fig. 11(c)).

The time history of the maximum stream function (Fig. 12) demonstrates that the eddy grows freely in the early stage (first ten time steps) but its growth is hindered by the wall and the cold liquid domain below during the intermediate stage. Each time step is $8 \mathrm{~s}$. The flow field reaches its quasi-steady state at the twentieth time step, beyond which $\left|\psi_{\text {max }}\right|$ takes an asymptotic value. A comparison of the two curves, $E v=0$ and -1 , suggests a significant enhancement in convection by the evolution of a cold plume in the presence of evaporation. The existence of a cold plume in Fig. 9(c) produces a single vortex in the final stage, in contrast to the formation of double vortices in the absence of phase change (Fig. 11(c)). In the former case, fluid motion will cease eventually because there is no heat sink in the flow field.

When the line source is replaced by a line sink in Fig. 1, condensation will occur over the free surface. In the analytical study, $\Delta T=0.14^{\circ} \mathrm{C}$ is employed. The flow field is essentially stable in the presence of condensation. The warm liquid layer stays beneath the free surface but a cold plume is formed near the line sink, Fig. 13(a). The difference between the evaporation and condensation is that the base of the plume in the former case moves, while that in the latter case remains stationary. Both surface tension and buoyancy forces drive the liquid toward the line sink along the temperature gradient, while gravity pulls down the cold liquid in the vicinity of the sink, thus forming an eddy. As time elapses, the plume disappears, Fig. 13(b), and the eddy is forced to move upward due to the buoyancy effect of the lower cold region. The more stable temperature distribution (with the cold liquid below the warm one) results in the secondary flow in the final stage, Fig. 14(c). The time history of positive $\psi_{\max }$ is superimposed in Fig. 

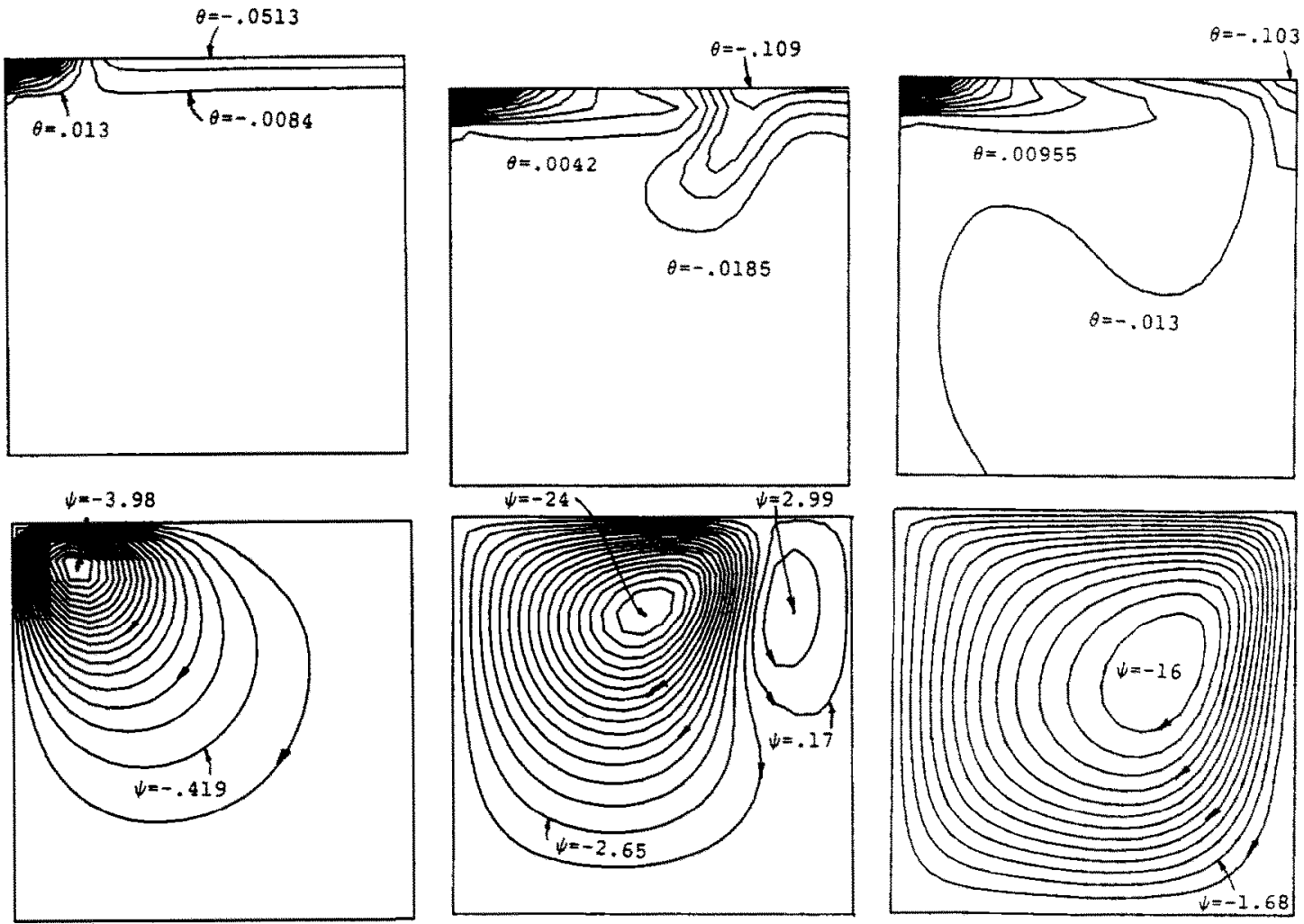

FIG. 9. Timewise variations of isotherms and streamlines in the Ra-driven convection in a low $M a$ system with $E v=-1, M a=100, R a=10^{6}, P r=5$ and $R H L=1$.
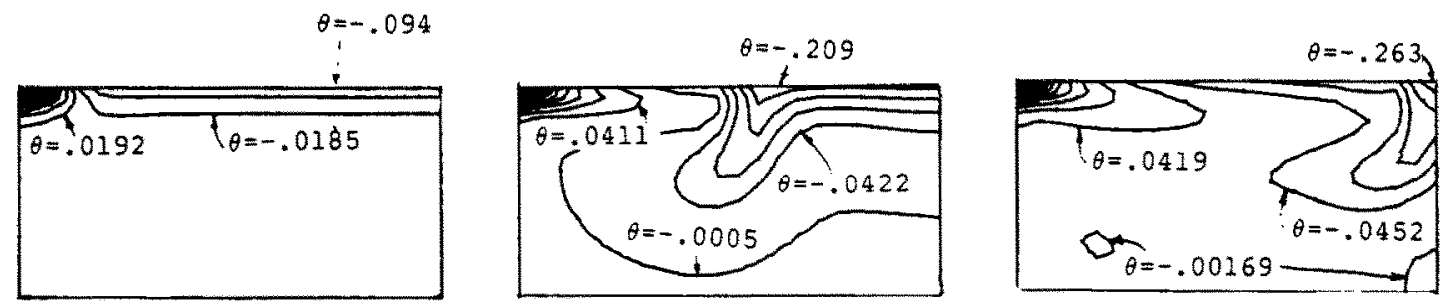

$$
\psi=-3.1
$$
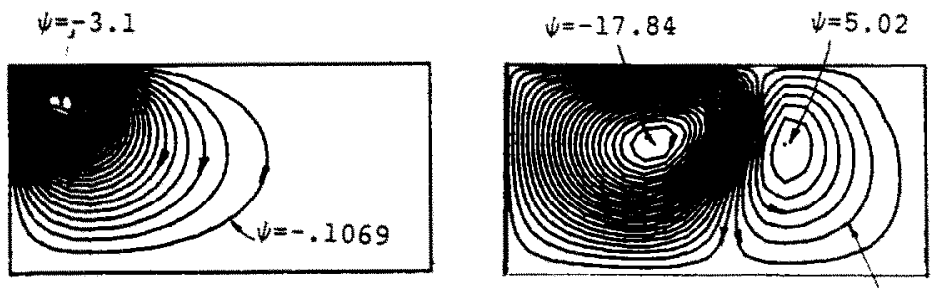

$\psi=1.0786$

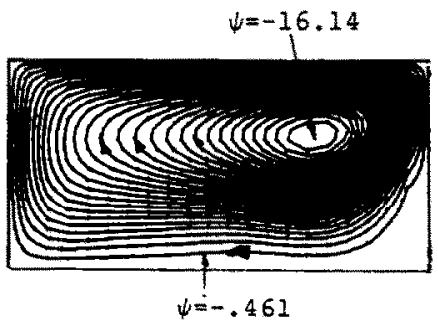

FIG. 10. Timewise variations of isotherms and streamlines in the mixed convection in a low Ma system with $E v=-1, M a=100, R a=10^{5}, \operatorname{Pr}=5$ and $R H L=0.5$.

12. During condensation, the interfacial temperatures increase almost uniformly. Very steep temperature gradients exist only in the vicinity of the line sink.

4.3.3. Effects of Rayleigh number. Buoyancy plays an important role in thermal stability when a cold liquid domain appears beneath the free surface during the evaporation process. When $R a$ is less than $R a_{c}$, convection is insensitive to $R a$ and is surface-tension controlled. However, the convection is significantly enhanced by the buoyancy force when $R a$ exceeds $R a_{\mathrm{c}}$. The critical $R a$ number for the onset of buoyancyinduced convection, $R a_{c}$, is 1000 in the present study. When $R a$ reaches $R a_{\mathrm{t}}$, buoyancy becomes so strong that the migration of the eddy is hindered by the wall. Thermal stratification is commonly observed in the range of $R a_{\mathrm{c}}<R a<R a_{\mathrm{t}}$ called the mixed convection 

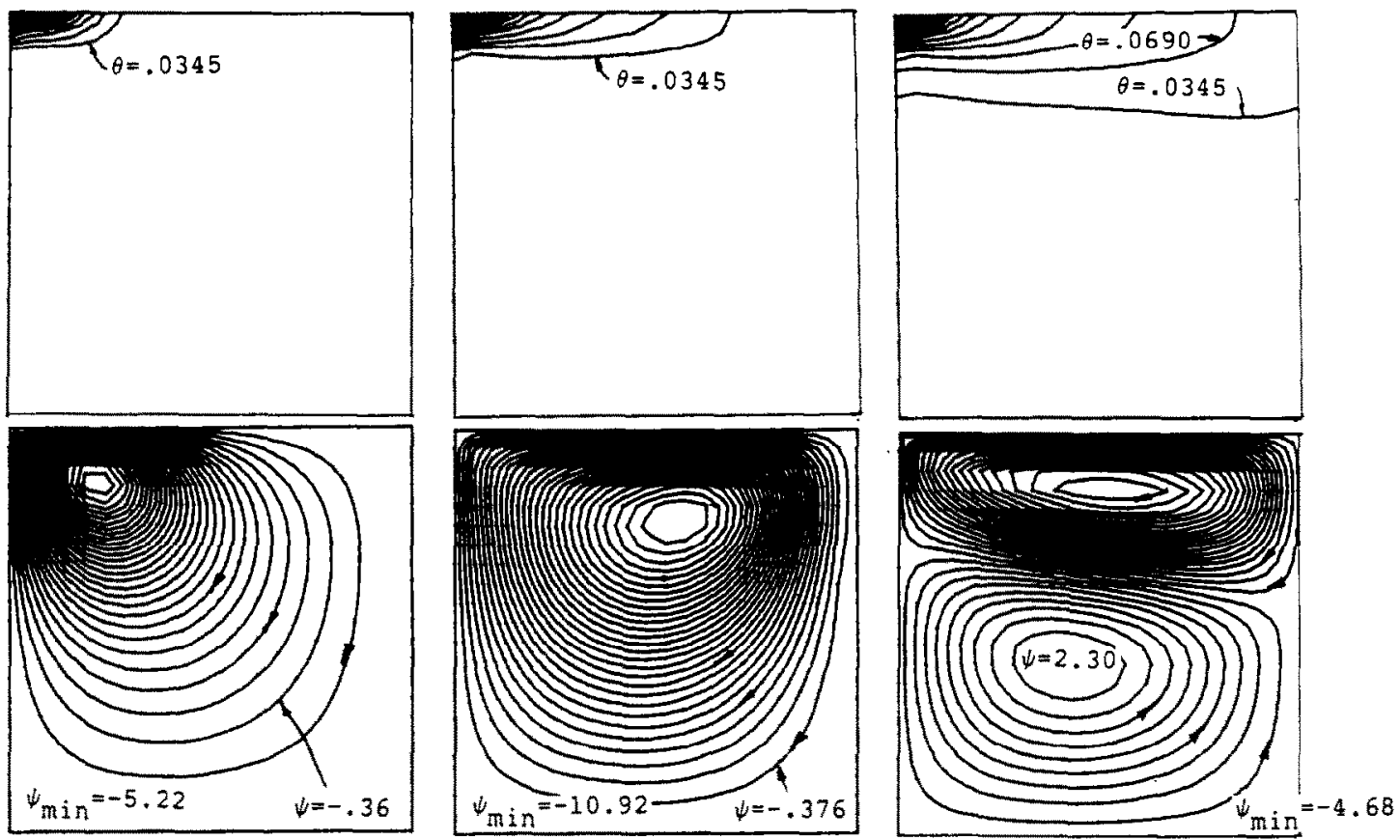

FIG. 11. Timewise variations of isotherms and streamlines in the Ra-driven convection in a system with $E v=0, M a=100, R a=10^{6}, P r=5$ and $R H L=1$.

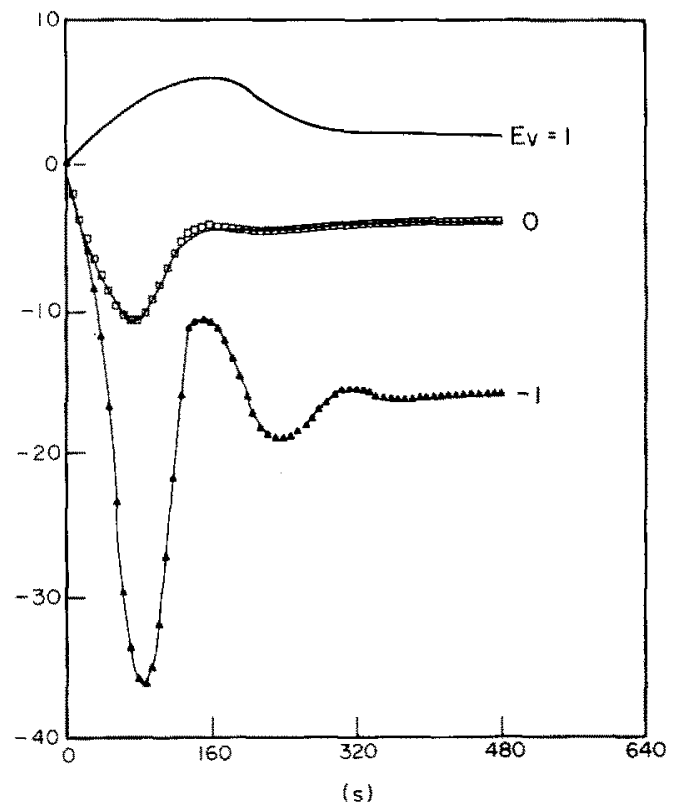

Fig. 12. Effect of $E v$ on the maximum stream function in the Ra-driven convection in the low $M a$ systems with $M a=100, R a=10^{5}, \operatorname{Pr}=5$ and $R H L=1$.

induced by a combined action of surface tension and buoyancy forces. When $R a$ exceeds a critical value, $R a_{1}$, the formation of a cold plume results from the appearance of a counter eddy. The fluid motion is at a transient state due to the unsteady nature caused by the presence of evaporation. It is called the $R a$ driven convection, being buoyancy controlled. In the present case $R a_{1}=10^{5}$.
4.3.4. Effects of Marangoni number. The higher $\mathrm{Ma}$ is, the lower the minimum temperature will be. When convection is $M a$-driven, i.e. $R a<R a_{\text {s }}$, flow is enhanced by an increase in $M a$. In a buoyancythermocapillary system, $M a$ plays a stabilizing role since it aids in spreading the warm liquid over the interface and supports heat loss through evaporation. Therefore, it suppresses the cold temperature region beneath the interface, which causes an unstable situation, and in turn stabilizes the flow field. In the mixed convection, i.e. $R a_{\mathrm{c}}<R a<R a_{\mathrm{t}}$, a higher $M a$ yields a more stable system with less formation of a cold plume.

4.3.5. Effect of Prandtl number. A change in Prandtl number produces no apparent effect on the transfer phenomena.

\section{CONCLUSIONS}

A finite-difference method has been employed to study unsteady buoyancy-thermocapillary convection in a rectangular tank with evaporation. The effects of governing dimensionless parameters, namely $E v, M a, R a, R H L$ and $P r$, on the flow instability and heat transfer behavior are determined. Flow visualization experiments have been conducted to observe isotherms and streamlines in ethyl alcohol. The conclusions given below are derived from the study.

Surface tension is a stabilizing agent in the flow field, while gravity acts as a destabilizer with evaporation to reinforce the buoyancy effect. There exists a critical 

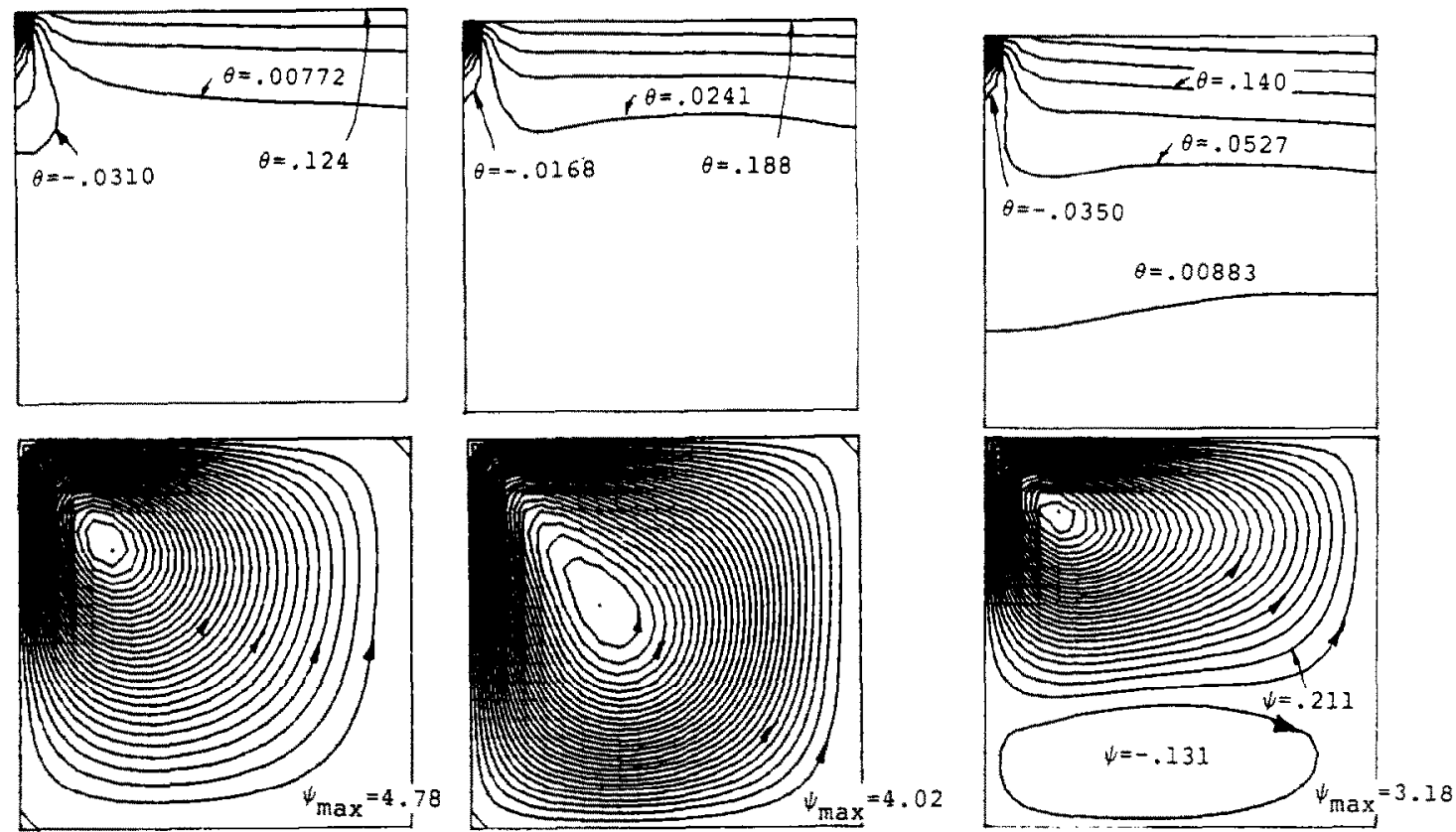

FIG. 13. Timewise variations of isotherms and streamlines in a condensing system with $E v=1, M a=50$, $R a=50, R a=10^{5}, P r=5$ and $R H L=1$.

value of $M a, M a_{\mathrm{c}}$, beyond which a higher $R a$ results in less convection. The magnitude of $M a_{\mathrm{c}}$ varies with the magnitude of $E v$. The high $M a$ system $\left(M a>M a_{\mathrm{c}}\right)$ is characterized by the formation of vertically aligned dual cells at steady state. Experimental observations of streamlines and isotherms are in good qualitative agreement with theoretical prediction.

In the low $M a$ range $\left(M a<M a_{\mathrm{e}}\right.$, the flow mechanisms can be classified into three kinds: $M a$-driven, mixed and $R a$-driven convections. The three regimes are divided by the magnitude of $R a$. The $M a$-driven flow for $R a<R a_{\mathrm{c}}$ is characterized by the downward migration of the warm cluster. No formation of cold plume occurs and the vortex center stays near the line source. In the mixed convection with $R a_{\mathrm{c}}<R a<R a_{\mathrm{b}}$ the vortex center migrates in the $\gamma$ form with time. The $R a$-driven regime, $R a>R a_{\mathrm{t}}$, is unique in the formation of a cold liquid plume, the initiation of transient stage to turbulent flow, the formation of a counter eddy and the radial migration of the main eddy away from the line source. There is no apparent effect of $\mathrm{Pr}$ on the transfer behavior. In case of no phase change, no cold stratification occurs and convection is weaker. At small times, the Ma-driven flow prevails with the vortex staying near the line source. The flow field becomes $R a$-controlled at large times. The vortex center moves toward the side wall and decays, forming vertically aligned dual cells. The effect of $R H L$ becomes evident only if the migration of the vortex center occurs, namely $R a>R a_{\mathfrak{c}}$. A shallow liquid layer is unstable during the evolution of eddies and becomes stabilized toward the steady state. A condensing system is stable since condensation results in a warmer liquid over the initially cold liquid at the bottom. It is similar to an evaporating system with high $M a$ (over $M a_{c}$ ), or similar to a system of no phase change at steady state.

Acknowledgement - The work was supported by the National Science Foundation under Grant No. MEA 8304740.

\section{REFERENCES}

1. L. G. Napolitano, Marangoni convection in space microgravity environments, Science 225, 197-198 (13 July 1984).

2. J. H. Burgoyne, A. F. Roberts and P. F. Quinton. The spread of flame across a liquid surface, I, Proc. Soc. London Ser. A 38, 39--53 (1968).

3. G. M. Oreper and J. Szekely, Heat and fluid-flow phenomena in weld pools, $J$. Fluid Mech. 147, 53-79 (1984).

4. A. J. Russo, Calculated transient two-dimensional Marangoni flow in a pulsed-laser weld pool, ASME Paper 85-HT/WA-36 (1985).

5. P. L. T. Brian, J. E. Vivian and D. C. Matiatos, Interfacial turbulence during the absorption of carbon dioxide into monoethanolamine, A.I.Ch.E. Jl 31, 28-36 (1967).

6. N. Zhang and Wen-Jei Yang, Evaporative convection in minute drops on a plate with temperature gradient, Int. J. Heat Mass Trunsfer 26, 1479-1488 (1983).

7. C. Y. Shieh, Unsteady buoyancy-thermocapillary convection in rectangular tanks with phase change, $\mathrm{Ph} . \mathrm{D}$. thesis, University of Michigan, Ann Arbor (1985).

8. M. R. Samules and S. W. Churchill, Stability of a fluid in a rectangular region heated from below, A.I.Ch.E. Jl 13, 77-86 (1967).

9. K. Aziz and J. D. Hellums, Numerical solution of the three-dimensional equations of motion for laminar natural convection, Physics Fluids 10, 314-324 (1967).

10. M. A. Leschziner, Practical evaluation of three finite difference schemes for the computation of steady-state recirculatory flows, Comput. Meth. appl. Mech. Engng 23, 293-312 (1980).

11. P. J. Roache, Computational Fluid Dynamics, p. 48. Hermosa, Albuquerque, New Mexico (1972). 


\section{ECOULEMENT THERMOCAPILLAIRE DE TRANSITION DANS DES RESERVOIRS RECTANGULAIRES AVEC CHANGEMENT DE PHASE}

Résumé-Une étude numérique et expérimentale est faite sur la convection naturelle de transition dans un réservoir rectangulaire isolé. Le liquide est soudainement chauffé par une ligne-source (ou refroidie par une ligne-puits) placée au centre de la surface libre pour créer une force thermocapillaire. L'évaporation ou la condensation se produit sur la surface libre. Une technique de différences finies est employée pour intégrer numériquement les équations non stationnaires de la vorticité et de la chaleur. Des résultats numériques sont obtenus pour déterminer les effets des paramètres adimensionnels sur les phénomènes de transfert. Dans un systeme évaporatif avec un nombre de Marangoni $(\mathrm{Ma})$ faible, on identifie trois mécanismes convectifs distincts: celui contrôlé par la tension interfaciale, celui contrôlé par la pesanteur et celui de type mixte. Dans le comportement de l'écoulement les différences sont faites entre condensation, évaporation et absence de changement de phase. La théorie est en accord qualitatif avec les expériences d'évaporation aux grandes valeurs de $\mathrm{Ma}$.

\section{INSTATIONÄRE KAPILLARSTRÖMUNG IN RECHTECKIGEN BEHÄLTERN MIT PHASENUMWANDLUNG}

Zusammenfassung-Es wird die instationäre natürliche Konvektion in einem adiabaten rechteckigen Behälter numerisch und experimentell untersucht. Die Flüssigkeit wird plötzlich von einer linienförmigen Wärmequelle beheizt oder von einer linienförmigen Wärmesenke gekühlt, die sich in der Mitte der freien Oberfläche befindet und dabei Kapillarkräfte hervorruft. An der freien Oberfläche findet Verdampfung bzw. Kondensation statt. Es wird ein Finite-Differenzen-Verfahren angewandt, um die unstetigen Wirbelund Wärmetransportgleichungen numerisch zu integrieren. Man erhält numerische Ergebnisse, um die Einfüsse der dimensionslosen Erhaltungsparameter auf die Transportvorgänge zu bestimmen. In einem System mit Verdampfung bei kleinen Marangonizahlen werden drei verschiedene Konvektionsmechanismen erkannt : durch Oberflächenspannung angetriebene, durch Dichteunterschiede angetriebene und Misch-Formen. Unterschiedliches Strömungsverhalten zeigt sich bei Kondensation, Verdampfung und Vorgängen ohne Phasenumwandlungen. Die Theorie stimmt qualitativ mit Verdampfungsexperimenten bei großen Marangoni-Zahlen überein.

\section{ПЕРЕХОДНОЕ ТЕРМОКАПИЛЛЯРНОЕ ТЕЧЕНИЕ С ФАЗОВЫМИ ПРЕВРАЩЕНИЯМИ В ПРЯМОУГОЛЬНЫХ ЕМКОСТЯХ}

Аннотация-Численно и экспериментально исследуется переходная естественная конвекдия в изолированном прямоугольном объеме. Жидкость мгновенно нагревается или охлаждается линейным источником тепла, расположенным в центре свободной поверхности для создания термокапилдярной силы. На свободной поверхности происходят испарение и конденсация. Для численного интегрирования уравнений нестационарного вихревого движения и теплопереноса используется конечно-разностный метод. Полученные числениые результаты применяются для определения влияния безразмерных управляющих параметров на явления переноса. B испарительной системе при малом числе Марангони (Ma), выявлены три различных конвективных механизма: обусловленные поверхностным натяжением, подъемной силой и смешанный. Возникающие типы течения распределены между случаями конденсации, испарения и отсутствия Фазового преврашения. Теория качественно согласуется с экспериментами по испарению для систем с болышими $\mathrm{Ma}$. 